\title{
Evaluation of Eco-Environmental Quality and Analysis on Spatio-Temporal Variation in Jinan, China
}

\author{
Jian Cui ${ }^{1}$, Mingshui Zhu' ${ }^{1}$, Hongzhi Mi', Yaohui Liu ${ }^{1,2,3 *}$ \\ ${ }^{1}$ School of Surveying and Geo-Informatics, Shandong Jianzhu University, China \\ ${ }^{2}$ Hebei Key Laboratory of Earthquake Dynamics, Sanhe, China \\ ${ }^{3}$ School of Earth and Environmental Sciences, The University of Queensland, Brisbane, Australia
}

Received: 13 May 2021

Accepted: 18 July 2021

\begin{abstract}
Rapid and accurate evaluation of ecological environmental quality and analysis of spatio-temporal changes has important practical significance for Jinan, China, which is in a critical period of rapid economic and social development, leading to the contradiction between ecological environment and urban development increasingly prominent. In this study, we utilized Landsat 5/TM and Landsat 8/ OLI images to construct the remote sensing ecological index (RSEI) for evaluating and analyzing the ecological quality of Jinan from 2006 to 2018. The results indicate that the ecological environmental quality of Jinan is in a satisfied order. The RSEI of Jinan increased slightly from 2006 to 2018 and the area of improving environmental quality accounted for $32.78 \%$. By contrast, the area of decreasing ecological environmental quality only accounted for $18.40 \%$, indicating that the overall ecological environmental quality of Jinan was in an improving trend in recent years. The ecological quality of the southern mountainous area changed greatly and the ecological environment improved obviously, while the ecological environmental quality of the central urban area was relatively stable. The results provide a guidance for local government and data support for ecological protection in the context of rapid urbanization.
\end{abstract}

Keywords: ecological environmental quality, spatio-temporal variation, remote sensing ecological index, principal component analysis (PCA), Jinan

\section{Introduction}

The ecological environment is the basis of human survival and sustainable development, which plays an essential role in the development of human society.

e-mail: liuyaohui20@sdjzu.edu.cn
With the rapid progress of global urbanization, the ecological environment problem is one of the most important global problems that human beings are facing at present. Sea level size [1, 2], decreasing of forest resources [3], flood disaster [4], vegetation degradation $[5,6]$, urban heat island effect $[7,8]$, soil pollution [9, 10], disaster risk [11, 12] and other ecological environment problems seriously threaten 
the survival and development of human beings. Therefore, dynamic and continuous monitoring of the temporal and spatial changes of ecological environment quality has gradually become the focus of academic circles and relevant government departments, which does vitally help to the healthy and sustainable development of urban construction.

Scholars continue to promote the research of eco-environmental quality evaluation, bringing the evolutions of the theoretical methods, data acquisition and technical means of eco-environmental quality evaluation. Among them, remote sensing technology has become an effective tool and has been widely used in eco-environmental quality evaluation because of its advantages in long-time series, wide detection range and reliable data. Li et al. used remote sensing technology to analyze the land use and land cover change pattern of Qinghai Lake Basin from 1977 to 2004, and discussed the main environmental problems of Qinghai Lake Basin [13]; Some scholars analyzed the changes in ecological environment quality in forest, grassland, farmland and other areas by calculating vegetation net primary productivity [14], as well as the changes of environmental quality by analyzing single factors such as landscape pattern $[15,16]$ and urban heat island effect [17]. However, the single ecological index cannot accurately reflect the total eco-environment, which cannot objectively and fairly representing the changes of eco-environment quality. Therefore, a comprehensive index is needed to evaluate the complex urban ecological environment comprehensively and objectively.

$\mathrm{Xu}$ proposed the new remote sensing-based ecological index (RSEI) to evaluate the regional ecological environmental quality [18]. This index is completely based on remote sensing information technology and can obtain surface information objectively and quantitatively, which has a certain significance in environmental quality evaluation. Yue et al. used the RSEI to analyze the spatial and temporal distribution characteristics of ecological conditions in 35 major cities in China [19]. Hang et al. applied the RSEI model to assess ecological quality changes in Nanjing from 2000 to 2018 using Landsat 5 and Landsat 8 images combined with meteorological observations and socio-economic data [20]. Rukeya Sawuti et al. detected and evaluated the dynamic change of ecological environmental quality in Fukang by calculating the RSEI. Results show that unscientific land use leads to the decline of ecological environmental quality in Fukang [21]. Xiong et al. utilized RSEI to assess the impact of rubber plantation expansion on the quality of the ecological environment [22]. Zhang et al. used the ecological index to evaluate the ecological environmental quality of Qilian Mountain National Park [23]. These researches have demonstrated the effectiveness of the RSEI method and can realize the objective evaluation of ecological environmental quality, also has a high practical significance and reference value.

In recent years, as the capital of Shandong Province, Jinan has developed rapidly with continuous expansion, bringing dynamic changes in the urban ecological environment. At present, the related researches on the ecological environmental quality evaluation of Jinan mainly focus on the single ecological environment index of air quality [23-25], water resources environment $[26,27]$, soil quality [28, 29]. To our best knowledge, the research on the ecological environmental quality evaluation of Jinan is rare. The mechanism and driving factors of long-time series change of ecological environment in Jinan are not clear either.

Here, based on Landsat remote sensing images, this manuscript uses the principal component analysis (PCA) method to construct the RSEI model to quantitatively evaluate the ecological environment of Jinan from 2006 to 2018 by integrating humidity, greenness, and thermal dryness indexes and analyzes the spatiotemporal change process of ecological environmental quality. Combined with the development characteristics of Jinan, this manuscript analyzes the evolution law of ecological environment in southern mountainous areas and central urban areas in detail, to provide some reference suggestions for the protection of the natural environment and ecological environment construction in Jinan, as well as to serve the coordinated development of social economy and ecological environment in Jinan.

\section{Materials and Methods}

\section{Research Area}

Jinan $\quad\left(114^{\circ} 11^{\prime} \mathrm{E}-117^{\circ} 44^{\prime} \mathrm{E}, \quad 36^{\circ} 01^{\prime} \mathrm{N}-37^{\circ} 32^{\prime} \mathrm{N}\right)$ is located in the central region of Shandong Province, south of Mount Tai, north of the Yellow River. The terrain is high in the south and low in the north [30], characterized by distinct monsoons and four distinct seasons. The annual average temperature is $13.5^{\circ} \mathrm{C}-15.5^{\circ} \mathrm{C}$, and the precipitation is $600-900 \mathrm{~mm}$. In this paper, 8 districts and 2 counties in Jinan are selected as the study area (Due to historical reason, the original Laiwu was not included in Jinan, so this area is not considered). 8 districts refer to Lixia District, Shizhong District, Huaiyin District, Tianqiao District, Licheng District, Changqing District, Jiyang District, Zhangqiu District, 2 counties refer to Shanghe County and Pingyin County. We selected the southern mountainous area and the central urban area for indepth study. The southern mountainous area includes the whole area of Zhonggong Sub-district Office, Liubu Sub-district Office, and Xiying Town; The central urban area refers to the area delineated by the Jinan Master Plan (2011-2020) [31], and the scope of the study area is shown in Fig. 1. 


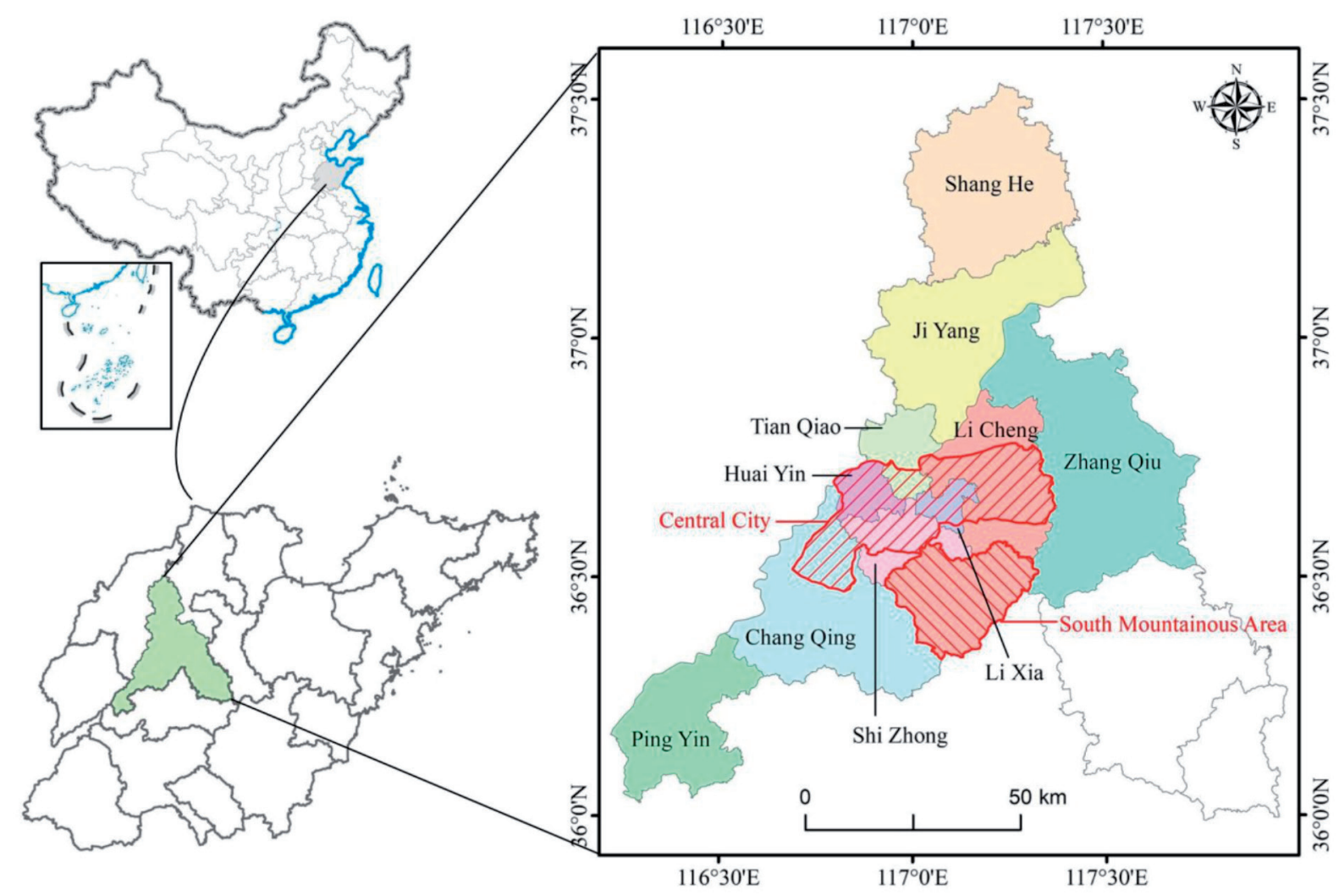

Fig. 1. The location of the research area.

Materials

We utilized Landsat 5/TM and Landsat 8/OLI images to construct the RSEI model. Landsat series remote sensing images provided by the website of the United States Geological Survey (https:/www.usgs. gov/). Remote sensing images in 2006, 2010, 2013, and 2018 are selected. The time phase is the same, and the cloud cover is less than $6 \%$ from April to May. The image quality is high, which can ensure the accuracy and comparability of the research results. Table 1 presents the details of experimental data in this paper. To avoid the influence of the atmosphere, illumination, and other factors on the processing accuracy of remote sensing images in different years, this study employed the absolute calibration method to calibrate the image. Then, the FLAASH atmospheric correction module was used for atmospheric correction, and finally, the image was mosaic and cut according to the boundary outline of the study area [33].

\section{Methods}

RSEI is a quantitative evaluation method integrating a variety of ecological indicators based on remote sensing information. The index is composed of four indicators: green degree, humidity, dry degree, and heat degree [33], and is integrated by the PCA method. The RSEI model has been widely applied in urban ecological environment assessment.

\section{Evaluation Index Calculation}

RSEI is constructed by integrating four indicators of greenness, wetness, dryness, and heat. In this paper, we chose the Normalized Difference Vegetation Index (NDVI) as our greenness indicator [34]. The wetness index is represented by the humidity component in the tasseled cap transformation $[35,36]$. The study area includes bare soil and urban built-up area, so the Normalized Difference Build and Soil Index (NDBSI) is generated by the combination of the Soil Index (SI) and the Index-based Built-up Index (IBI) [37, 38]. The heat index is represented by the inversion results of land surface temperature (LST). The Radiative Transfer Equation is used to invert the surface temperature to obtain the surface temperature [39]. We employed the normalization in calculating these indexes for weakening the influence of spectral sensitivity between Landsat TM and OLI data. The flowchart is shown in Fig. 2.

In Fig. $2, \rho_{B}, \rho_{G}, \rho_{R}, \rho_{\text {NIR }}, \rho_{\text {SWIR1 }}, \rho_{\text {SWIR } 2}$ represent the reflectance of bands $1-5$ of the Landsat $5 / \mathrm{TM}$ image and the bands 2-6 of the Landsat 8/OLI image, respectively. $\mathrm{L}_{\lambda}$ is the radiance at the sensor; $\varepsilon$ is the land surface emissivity; LST is the true surface temperature; $\mathrm{B}(\mathrm{LST})$ is the blackbody radiance given by Planck's law for a temperature LST; $\tau$ is the total atmospheric transmissivity between the land's surface and the sensor. $\mathrm{L}_{1}$ and $\mathrm{L}_{2}$ represent the upward and downward radiance of the atmosphere, respectively. $\mathrm{K}_{1}=607.76$ 
Table 1. Details of experimental data.

\begin{tabular}{|c|c|c|c|c|}
\hline Sensor type & Track number & Line number & Imaging time & Cloud cover \\
\hline \multirow{3}{*}{ Landsat5 TM } & 122 & 34 & $2006-05-02$ & $0.00 \%$ \\
\cline { 2 - 5 } & 122 & 35 & $2006-05-02$ & $2.00 \%$ \\
\cline { 2 - 5 } & 122 & 34 & $2010-04-27$ & $2.00 \%$ \\
\hline \multirow{3}{*}{ Landsat 8 OLI } & 122 & 35 & $2010-04-27$ & $4.00 \%$ \\
\cline { 2 - 5 } & 122 & 34 & $2013-05-21$ & $5.89 \%$ \\
\cline { 2 - 5 } & 122 & 35 & $2013-05-21$ & $0.87 \%$ \\
\cline { 2 - 5 } & 122 & 34 & $2018-05-16$ & $0.05 \%$ \\
\hline
\end{tabular}

$\mathrm{W} /\left(\mathrm{m}^{2} \cdot \mu \mathrm{m} \cdot \mathrm{sr}\right)$ and $\mathrm{K}_{2}=1260.56 \mathrm{~K}$ if obtained from the $\mathrm{TM}$, and $\mathrm{K}_{1}=774.89 \mathrm{~W} /\left(\mathrm{m}^{2} \cdot \mu \mathrm{m} \cdot \mathrm{sr}\right)$ and $\mathrm{K}_{2}=1321.08 \mathrm{~K}$ for the OLI.

\section{Construction of RSEI Model}

The RSEI adopts the PCA method to integrate the four ecological evaluation indexes of greenness, wetness, dryness, and heat. Since the calculation of the greenness index and dryness index in the water area is of little significance, to avoid this situation, it is necessary to use the modified normalized difference water index (MNDWI) to eliminate the water information of each index [40]. Due to the uniform dimensions of each index, the direct principal component analysis will lead to the imbalance of the weight of each index, which requires the normalization of each index. The normalization formula is as follows:

$$
N I_{i}=\frac{I_{i}-I_{\text {min }}}{I_{\max }-I_{\text {min }}}
$$

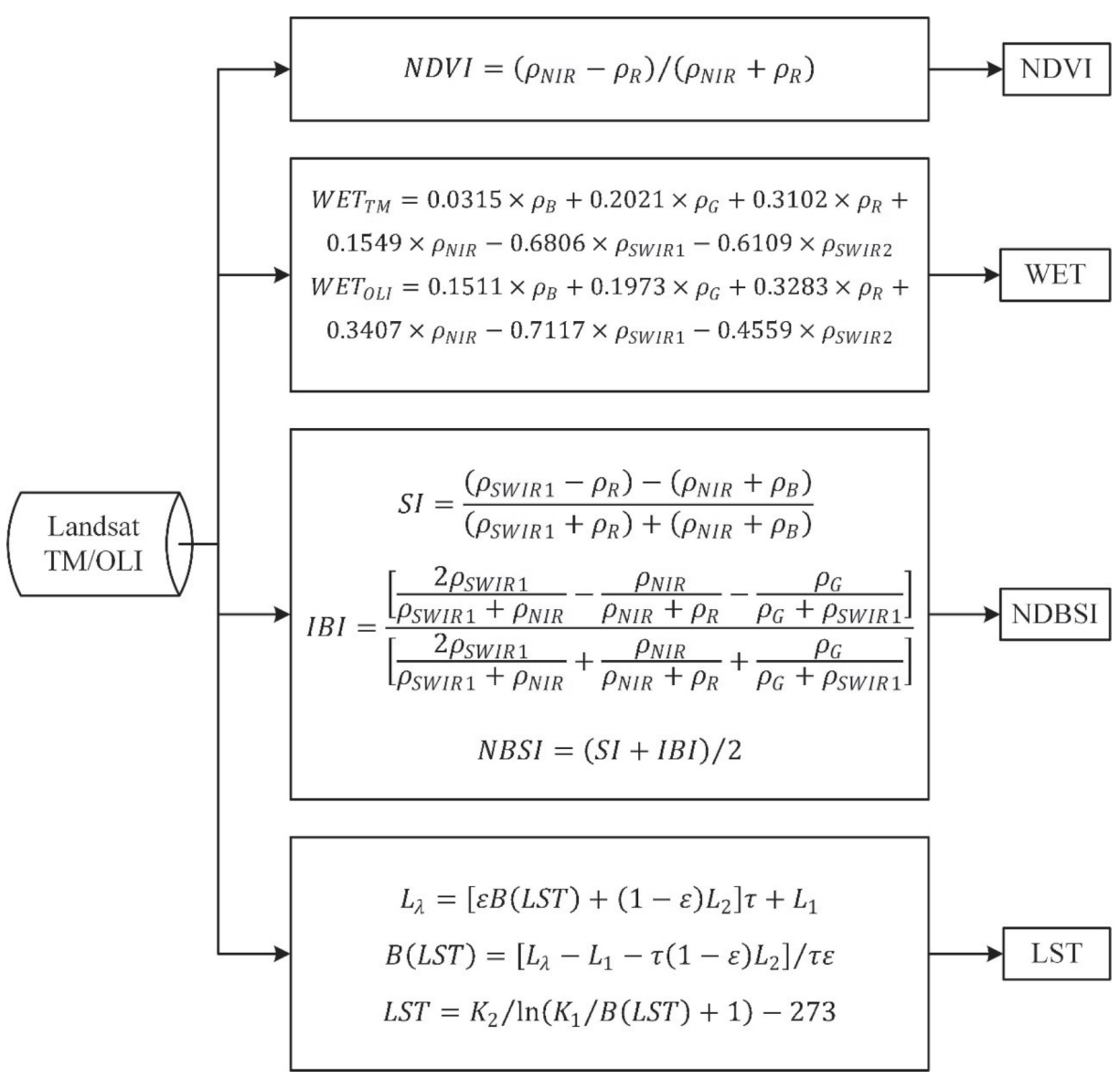

Fig. 2. The flowchart of the RSEI method. 
Where $N I_{i}$ is a normalized index value, $I_{i}$ is the original pixel value of this index, and $I_{\max }$ and $I_{\min }$ are the maximum and minimum of this index, respectively. Due to the lack of measured data, this paper intercepts the confidence interval according to the statistical histogram of each factor and finally determines that the confidence interval of each index factor is $2 \%$. The DN value of $98 \%$ is used as the confidence interval, and the data outside the interval is set to the maximum value, which can effectively avoid the influence of extreme values on normalization.

The processed index factors are analyzed by the PCA method, and the first principal component (PC1) is extracted for the calculation to obtain the initial value of RSEI, which is denoted as $\operatorname{RSEI}_{0}$ [41]. The calculation formula is as follows:

$$
R S E I_{0}=1-P C 1[f(N D V I, W E T, N D B S I, L S T)]
$$

Then normalized $R S E I_{0}$ is remote sensing ecological index (RSEI), the calculation formula is as follows:

$$
R S E I=\frac{R S E I_{0}-R S E I_{0_{\_} \min }}{R S E I_{0_{-} \max }-R S E I_{0_{-} \min }}
$$

The RSEI obtained by formula (3) has a range of $[0,1]$. The larger the RSEI value, the better the ecological environmental quality.

\section{Results and Discussion}

\section{Evaluation of Ecological Environmental Quality in Jinan}

Based on the RSEI model, we used remote sensing images from 2006, 2010, 2013, and 2018 to extract 4 index factors of NDVI, WET, NDBSI, and LST with PCA analysis, and selected the first principal component analysis after the principal component analysis. District ecological environmental quality status, the influence, and correlation of each index component on $\mathrm{PC1}$ are obtained, as shown in Table 2.

It can be seen from Table 2 that the contribution rate of the first principal component eigenvalue is more than
$80 \%$ in the results of principal component analysis of the data of four different periods, indicating that PC1 has contained most of the information of the four indicators. In addition, the load value of each index on $\mathrm{PC} 1$ is relatively stable, which meets the basic requirements of principal component analysis. Therefore, we can establish the remote sensing ecological index. The load values of green degree (NDVI) and humidity (WET) are both positive, indicating that they have positive effects on the ecological environment in Jinan. By contrast, the load values of dryness (NDBSI) and the heat (LST) are both negative, indicating that they both have negative effects on the ecological environment in Jinan.

Followed by the previous study [42], we subdivided RSEI into five sets of ratings at intervals of $(0-0.2$, $0.2-0.4,0.4-0.6,0.6-0.8$, and $0.8-1.0)$ : bad, poor, average, good and excellent, respectively. Through the reclassification process, the spatial distribution map of the ecological environmental quality grades is obtained and presented in Fig. 3. The areas with the good ecological environment in Jinan during the four periods are mainly distributed in the southern mountainous area and the northern plains area, while the areas with the relatively poor ecological environment are mainly concentrated in the urban built-up areas.

We conducted statistics and analyzed the proportion of ecological environmental quality grades in four different periods of Jinan City (Table 3). The result shows that the ecological environmental quality grade of Jinan is mainly good and medium, and the area ratio of them is always more than $50 \%$. The proportion of areas with poor grades is always lower than $5 \%$, indicating that the overall environmental quality of Jinan is in good condition from 2006 to 2018.

\section{An Analysis of Spatial and Temporal Differences in the Ecological Quality in Jinan}

To further analyze the temporal and spatial changes of ecological environmental quality in Jinan, we calculated the difference value of ecological environmental quality grade evaluation results in 2006, 2010, 2013, and 2018, and obtain the changes of ecological environmental quality in Jinan in these four periods (Fig. 4). The red area in Fig. 4 shows that the quality of the ecological environment is decreased, while the yellow area indicates that the ecological

Table 2. Change of load value of index PC1 in each year.

\begin{tabular}{|c|c|c|c|c|}
\hline Year & 2006 & 2010 & 2013 & 2018 \\
\hline NDVI & 0.50 & 0.64 & 0.43 & 0.48 \\
\hline WET & 0.45 & 0.42 & 0.54 & 0.56 \\
\hline NDBSI & -0.56 & -0.63 & -0.58 & -0.60 \\
\hline LST & -0.48 & -0.13 & -0.42 & -0.32 \\
\hline Contribution rate & $87.31 \%$ & $84.98 \%$ & $80.81 \%$ & $82.31 \%$ \\
\hline
\end{tabular}



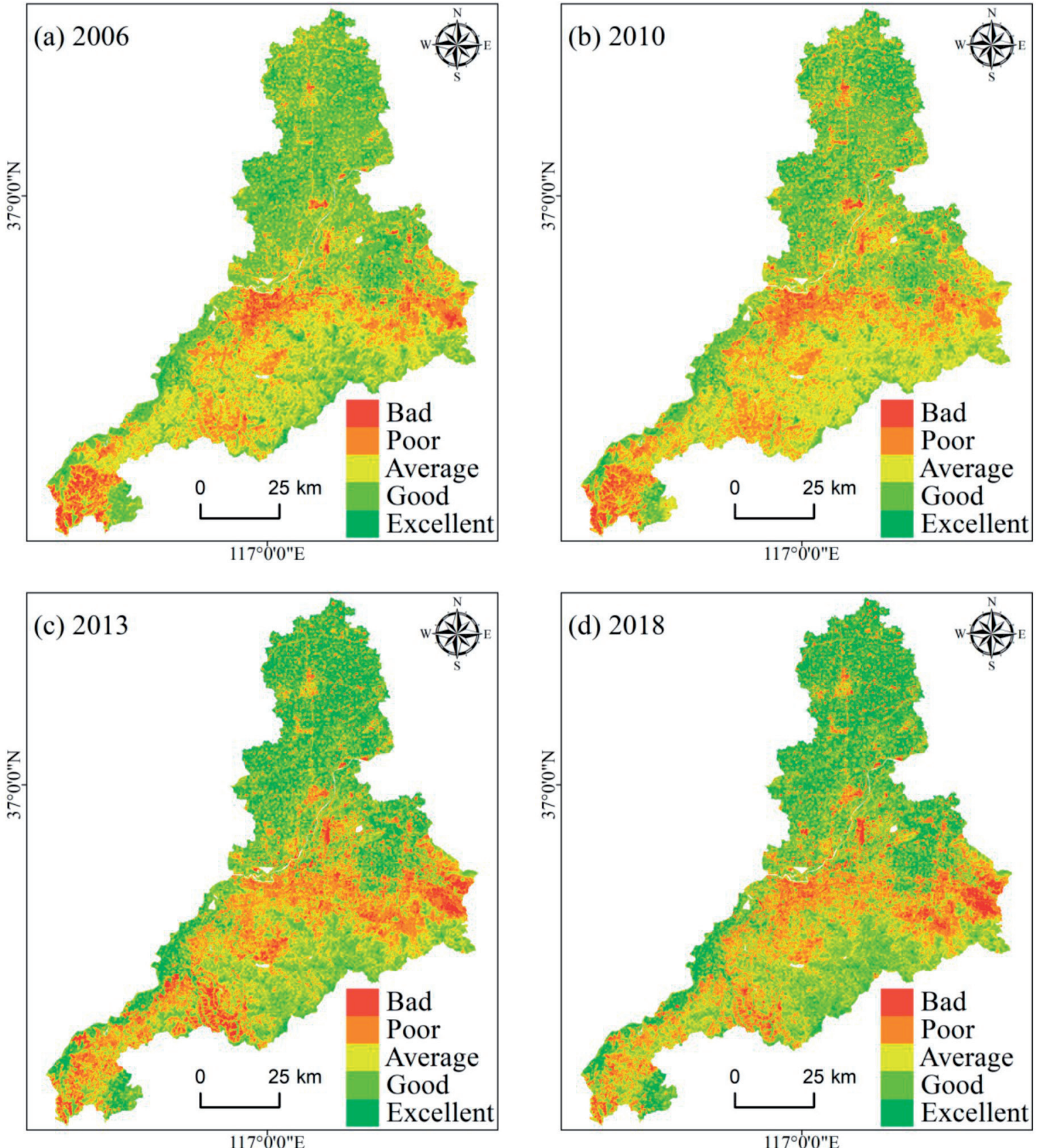

Fig. 3. Distribution of RSEI grades of Jinan from 2006 to 2018.

environmental quality has not changed, and the green area represents the improvement of the ecological environmental quality. From 2006 to 2010, the areas where the quality of the ecological environment in Jinan declined were mainly concentrated in the southern mountainous areas and the northern plains; from 2010 to 2013, the areas with improved ecological environmental quality in Jinan were mainly distributed in the southern mountainous areas; from 2013 to 2018. In 2006, the overall ecological environmental quality was mainly unchanged; from 2006 to 2018, the ecological environmental quality of Jinan was improved, and the improved areas were mostly distributed in the southern mountainous areas.
We conducted statistics on the area and proportions of the areas with ecological environmental quality levels in four different periods in Jinan (Table 4). The results show that from 2006 to 2010, the areas with unchanged ecological environmental quality accounted for the largest area, accounting for $73.35 \%$. The area with deterioration accounted for $17.92 \%$, Conversely, the area with improvement was $8.74 \%$, which suggests that the ecological environmental quality of the study area declined slightly during this period. From 2010 to 2013, the total area where the ecological level of the study area became better was $2560.54 \mathrm{~km}^{2}$, accounting for $32.32 \%$, on the other hand, the area of the deteriorating area only accounted for $16.92 \%$. 
Table 3. Statistical chart of ecological grades and area ratios in each year.

\begin{tabular}{|c|c|c|c|c|c|c|c|c|}
\hline \multirow{2}{*}{ Grade } & \multicolumn{2}{|c|}{2006} & \multicolumn{2}{c|}{2010} & \multicolumn{2}{c|}{2013} & \multicolumn{2}{c|}{2018} \\
\cline { 2 - 10 } & Area $\left(\mathrm{km}^{2}\right)$ & $\%$ & Area $\left(\mathrm{km}^{2}\right)$ & $\%$ & Area $\left(\mathrm{km}^{2}\right)$ & $\%$ & Area $\left(\mathrm{km}^{2}\right)$ & $\%$ \\
\hline Bad & 176.8 & 2.2 & 186.3 & 2.3 & 363.1 & 4.6 & 333.5 & 4.2 \\
\hline Poor & 1389.5 & 17.5 & 1688.8 & 21.3 & 1745.5 & 22.0 & 1649.2 & 20.8 \\
\hline Average & 2781.7 & 35.1 & 3023.8 & 38.2 & 2102.2 & 26.5 & 1950.2 & 24.6 \\
\hline Good & 3112.8 & 39.3 & 2442.1 & 30.8 & 2181.9 & 27.5 & 2304.1 & 29.1 \\
\hline Excellent & 461.2 & 5.8 & 581.4 & 7.3 & 1529.8 & 19.3 & 1685.4 & 21.3 \\
\hline
\end{tabular}
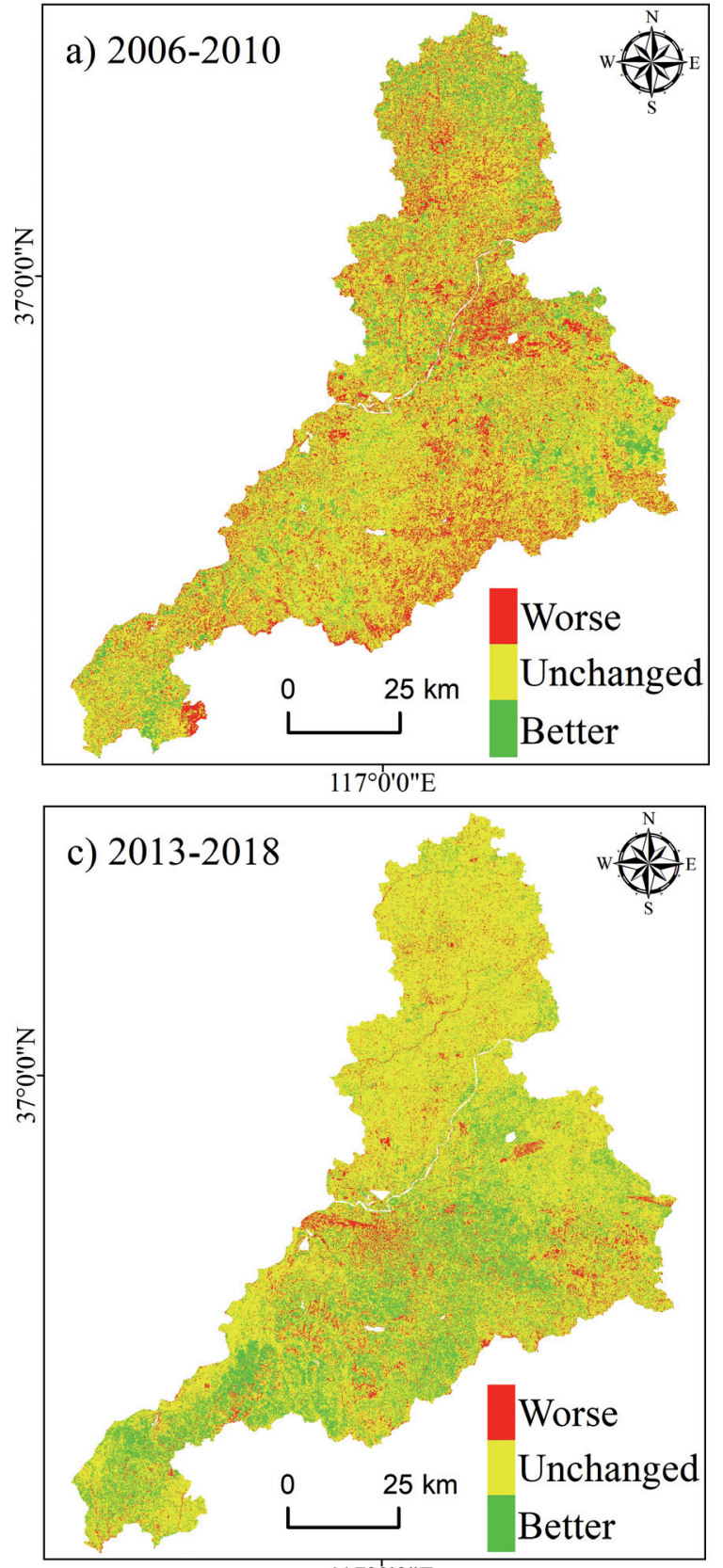

$117^{\circ} 0^{\prime} 0^{\prime \prime} \mathrm{E}$

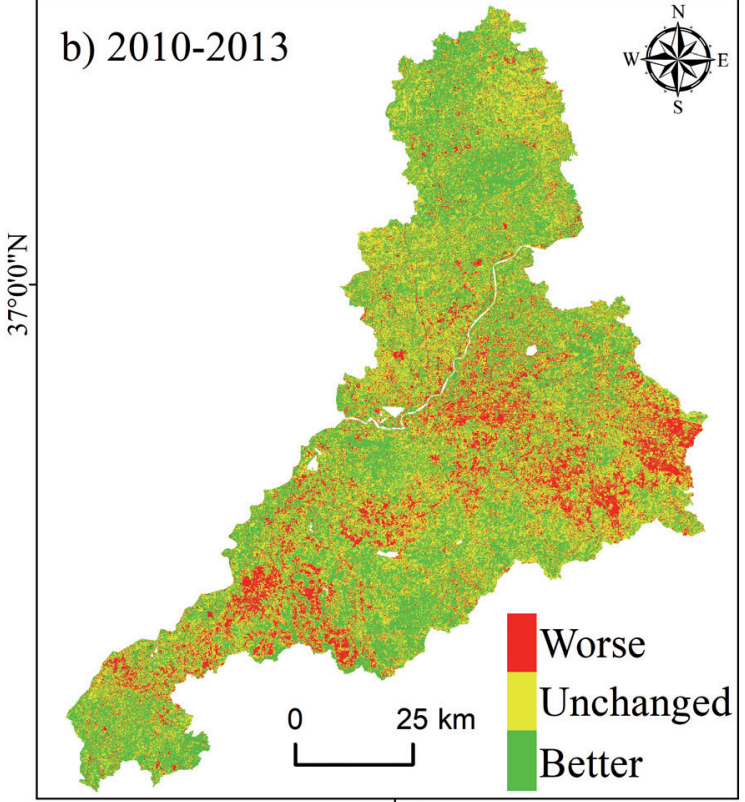

$117^{\circ} 0^{\prime} 0 " \mathrm{E}$

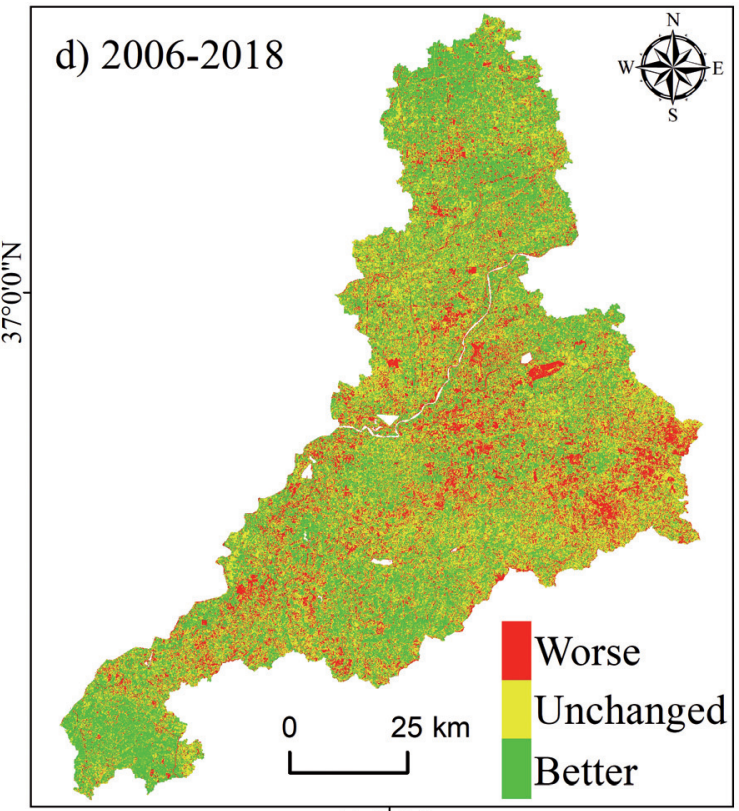

$117^{\circ} 0^{\prime} 0 " \mathrm{E}$

Fig. 4. Changes of the RSEI of Jinan from 2006 to 2018. 
Table 4. Changes in ecological environmental quality in each year.

\begin{tabular}{|c|c|c|c|c|c|c|c|c|}
\hline \multirow{2}{*}{ Category } & \multicolumn{2}{|c|}{$2006 \sim 2010$} & \multicolumn{2}{c|}{$2010 \sim 2013$} & \multicolumn{2}{c|}{$2013 \sim 2018$} & \multicolumn{2}{c|}{$2006 \sim 2018$} \\
\cline { 2 - 9 } & Area $\left(\mathrm{km}^{2}\right)$ & $\%$ & Area $\left(\mathrm{km}^{2}\right)$ & $\%$ & Area $\left(\mathrm{km}^{2}\right)$ & $\%$ & Area $\left(\mathrm{km}^{2}\right)$ & $\%$ \\
\hline Worse & 1419.3 & 17.9 & 1277.2 & 16.1 & 535.1 & 6.8 & 1457.6 & 18.4 \\
\hline Unchanged & 5810.7 & 73.4 & 4084.6 & 51.6 & 6235.9 & 78.7 & 3867.6 & 48.8 \\
\hline Better & 692.3 & 8.7 & 2560.5 & 32.3 & 1151.3 & 14.5 & 2597.2 & 32.8 \\
\hline
\end{tabular}

Accordingly, the ecological environmental quality of the study area was significantly improved during this period. From 2013 to 2018, the area with the same ecological quality level was $6235.96 \mathrm{~km}^{2}$, accounting for $78.71 \%$. The areas with better and worse ecological quality levels were $14.53 \%$ and $3.75 \%$, respectively, indicating that the ecological environmental quality of the study area has improved during this period. From the perspective of the total 12-year trend, the area of the study area with better ecological grade accounted for $32.78 \%$, while the area with reduced ecological environmental quality accounted for $18.40 \%$. Results show that the environmental quality in Jinan increased after the decline with an overall upward trend of "V"shaped change from 2006 to 2018.
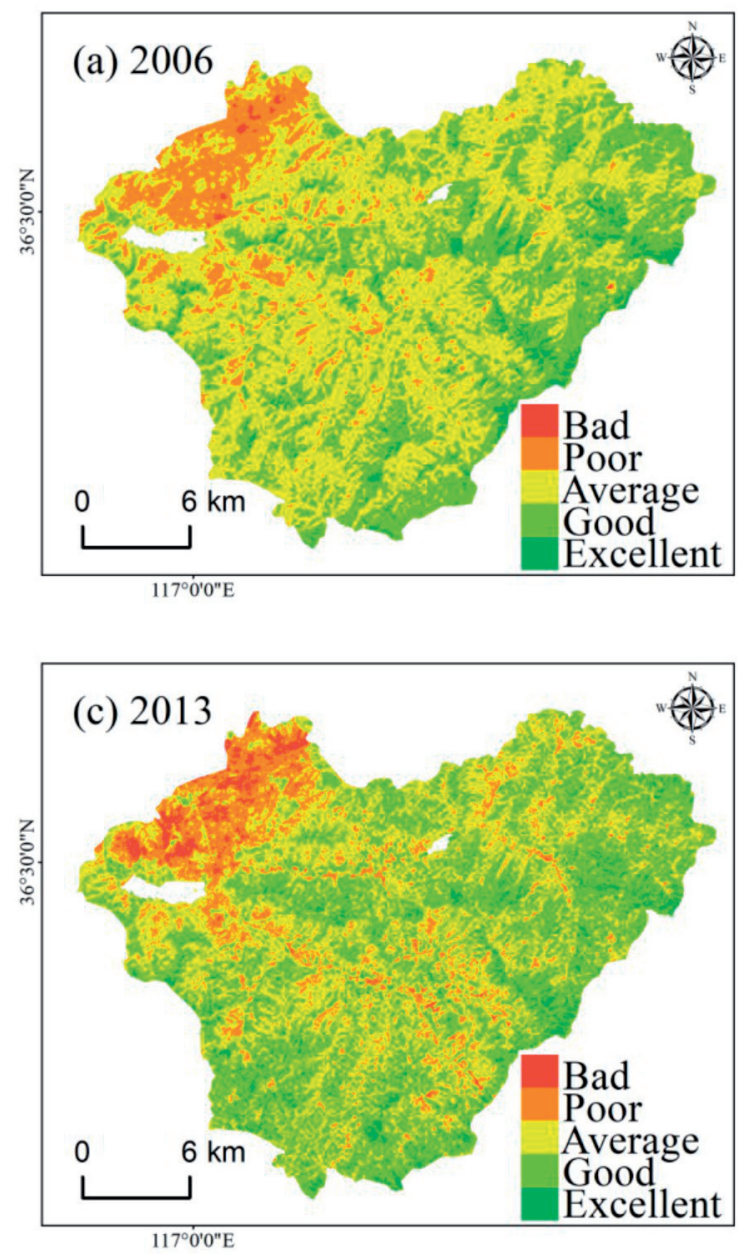

Assessment of Ecological Changes of Characteristic Ecological Regions in Jinan

By analyzing the temporal and spatial evolution of Jinan, it is found that the ecological environmental quality in the southern mountainous area and the central urban area of Jinan has obvious characteristics. Therefore, to explore the evolution characteristics of the ecological environment in key areas of Jinan, this section focuses on the analysis of the environmental quality and its influencing factors in the southern mountainous area and central urban area of Jinan, to provide some references for the protection of the natural environment and ecological environment construction.
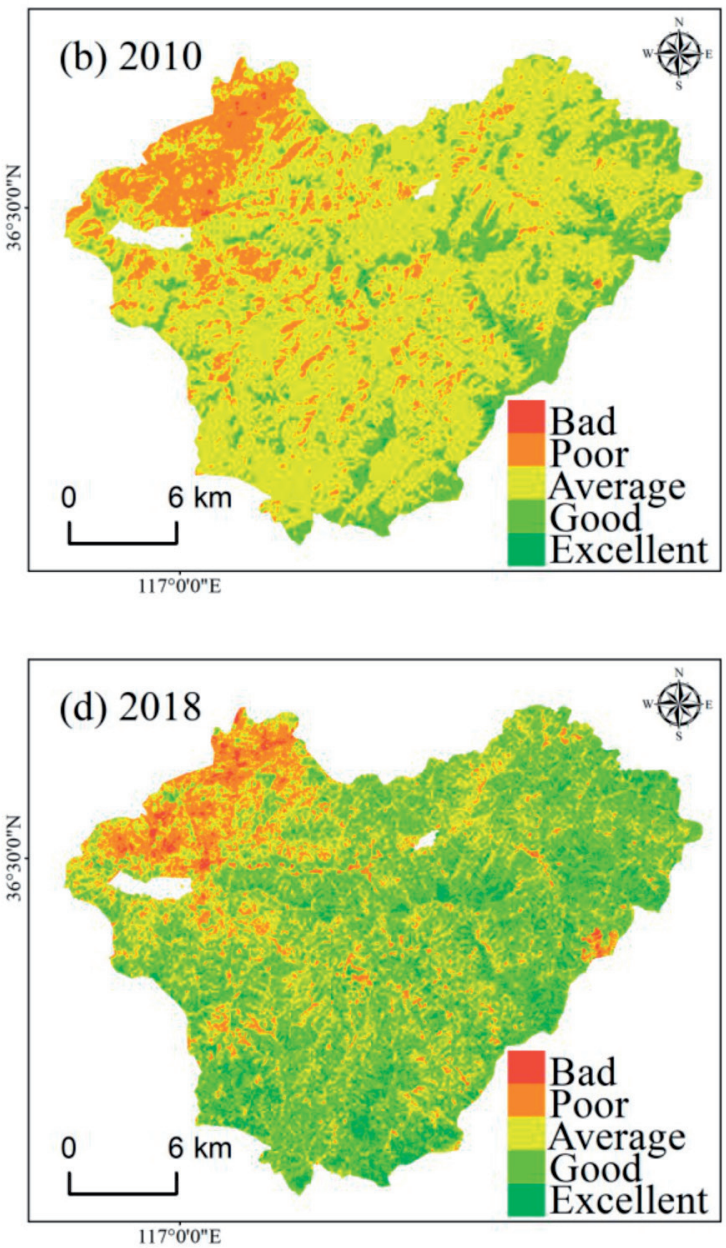

Fig. 5. Changes of the RSEI in the Southern Mountain Region of Jinan from 2006 to 2018. 


\section{Assessment of Ecological Changes of the Southern Mountain Area}

The southern mountainous area is the key ecological protection area of Jinan. The ecological environmental quality of the southern mountainous area of Jinan from 2006 to 2018 is displayed in Fig. 5. The ecological environmental quality level of the southern mountainous area in 2006 is mainly good and medium. And the area with middle ecological grade expanded in 2010 and the ecological environmental quality declined slightly. Moreover, the ecological environmental quality has been significantly improved in 2013, the grades are mainly excellent. Ecological environmental quality in 2018 is similar to that in 2013.

The local government of Jinan actively implements the south control strategy, and improves the vegetation coverage through measures such as returning farmland to forests, afforestation of barren hills, restoration and management of mining areas, and construction of nature reserves, scenic spots, and forest parks. At present, the forest coverage in the southern mountainous area is more than $60 \%$, and the soil erosion is effectively controlled. Through the construction of ecological agriculture, ecological industry, and ecological tourism, the sustainable development capacity of the southern mountainous areas has been improved, which has effectively improved the quality of the local ecological environment.
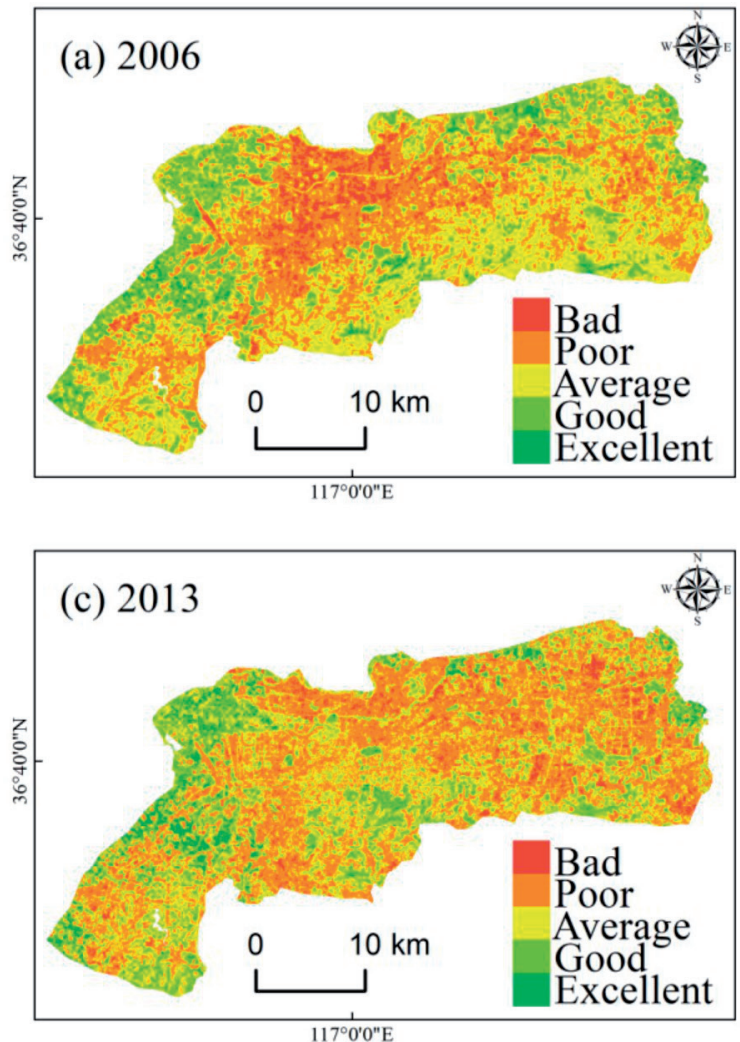

\section{Assessment of Ecological Changes of the Central Urban Area}

Through the analysis of the grade distribution map of the ecological environmental quality in the central urban area of Jinan from 2006 to 2018 (presented in Fig. 6 ), it is clear that the ecological environmental quality in the central urban area of Jinan is relatively stable. The declining areas of the ecological environmental quality in the central urban area are distributed in the east of the urban area. This is because the built-up area gradually expands eastward, and the construction area of the region continues to increase and the vegetation coverage decreases, leading to a decline in the ecological environment index in the eastern part of the urban area in Jinan.

Based on the RSEI model, this paper evaluates the ecological environment of Jinan. The method objectively describes the ecological environmental quality of Jinan and can analyze the spatial and temporal changes of the ecological environmental quality reasonably. Due to the low resolution of the selected image, there are some shortcomings in the final evaluation results, so a higher resolution remote sensing image should be considered in future research.

The change of ecological environmental quality in Jinan is caused by natural factors, urban construction, and other aspects. From the perspective of natural factors, Jinan is located in the south of the Yellow River and the north of Mount Tai. The terrain is mainly
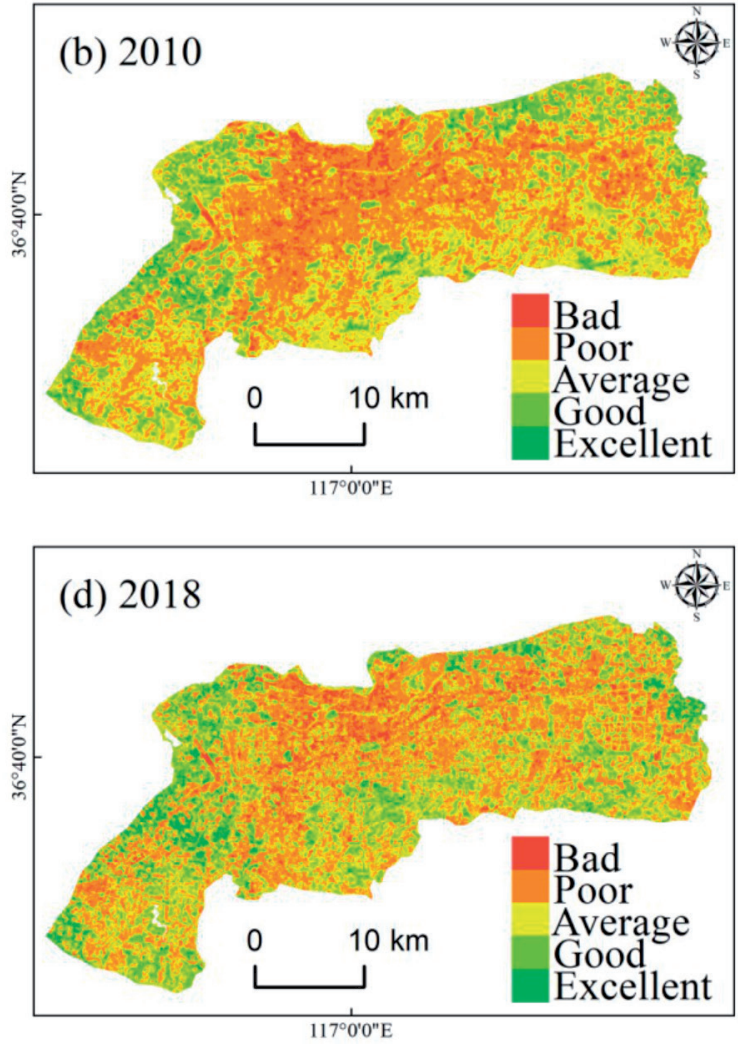

Fig. 6. Changes of the RSEI in the Central City of Jinan from 2006 to 2018. 


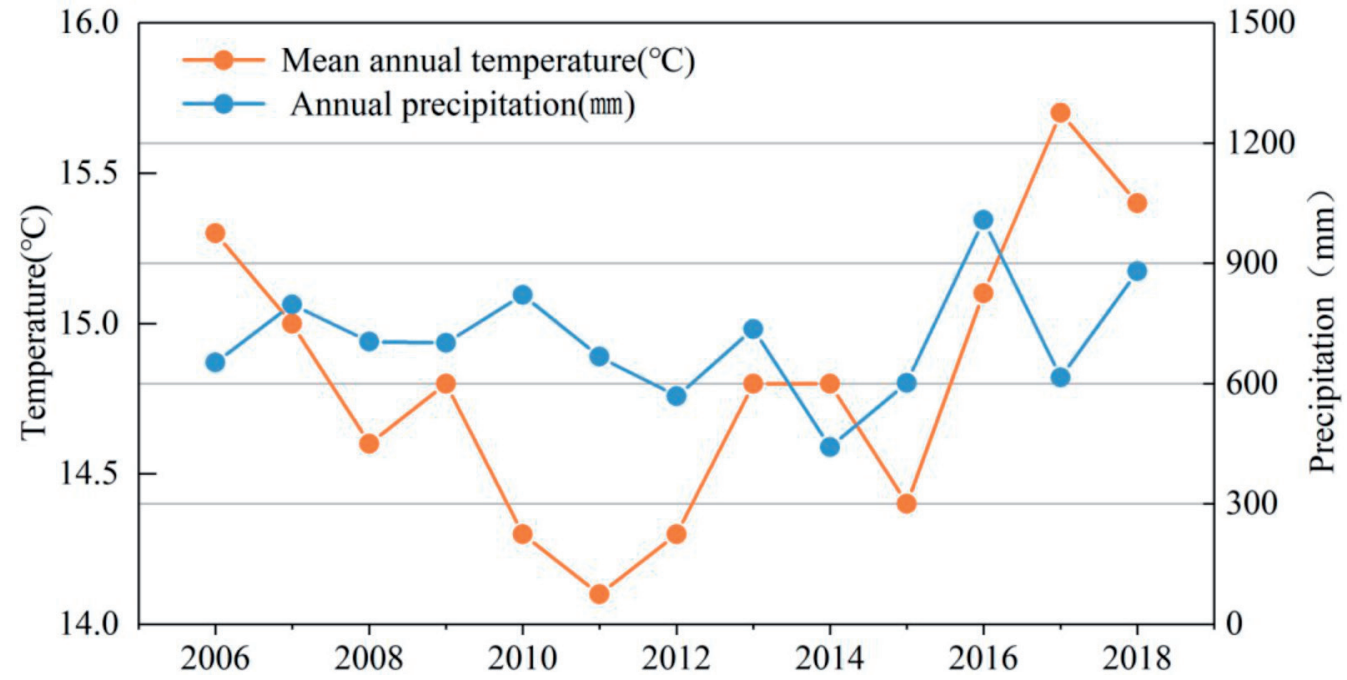

Fig. 7. Changes in precipitation and temperature from 2006 to 2018.

composed of hills and plains. Natural factors such as precipitation and temperature play a certain role in the change of ecological environmental quality. As shown in Fig. 7, the annual average temperature of Jinan from 2006 to 2018 showed a trend of the first decrease and then increase, while the annual precipitation showed a slight fluctuation and a slow upward trend. The average NDVI value of the green index decreased from 0.47 in 2006 to 0.41 in 2010 and then increased to 0.52 in 2018. The mean NDBSI, which was negatively correlated with the ecological environment, rising from 0.59 in 2006 to 0.62 in 2010 and then fell to 0.54 in 2018. In general, the above results show that the increase of temperature and higher precipitation contribute to the growth of vegetation and improve the quality of the ecological environment. Therefore, climate change affects the quality of the ecological environment to a certain extent.

From the perspective of urban construction in Jinan, the local government first put forward the cross-development policy of 'expanding to the East, advancing to the West, controlling to the South, crossing to the North and dispersing to the Middle' in 2003. After nearly 17 years, Jinan's urban development has deepened the implementation of the abovementioned policy. According to Fig. 8, it can be seen that from 2006 to 2018, the areas where the ecological environment quality of Jinan City increased

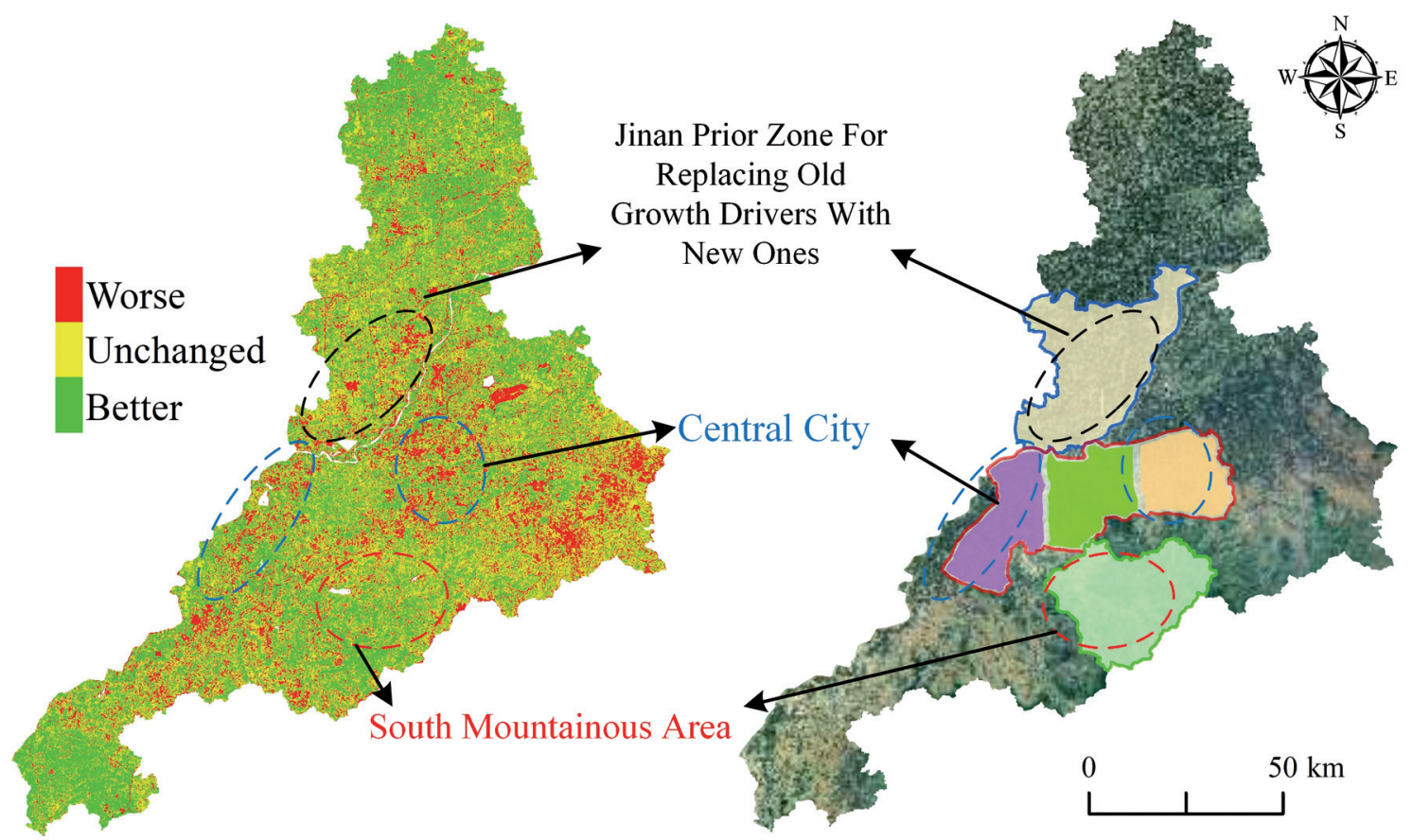

Fig. 8. The contrast between change images of RSEI from 2006 to 2018 and the plan map of Jinan City. 
only in the southern mountainous area and the northern plain area. The local government carried out a series of efforts, such as returning farmland to forest and afforestation and provided policy protection for the southern area, which made the vegetation coverage rate of the area increase year by year and effectively improved the ecological environment of the southern mountainous area. However, the northern plain area of Jinan City is flat with cultivated land and a relatively stable eco-environment. In the eastern and western areas of the central urban area, a large area of bare construction land has replaced the original green space due to the continuous expansion of the city, reducing the ecological environment quality of the area. With the implementation of the old and new kinetic energy conversion pilot area in Jinan, a large amount of farmland in this area has been converted into construction land, and the vegetation area has decreased, resulting in the decline of ecological environment quality. Therefore, it can be seen that the urban development policy has a great impact on the quality of the urban ecological environment in Jinan City.

\section{Conclusions}

In this paper, comprehensive research the spatial and temporal variation analysis of the ecological environment in Jinan City was performed using remote sensing technology. Landsat 5/TM and Landsat 8/OLI images were utilized to construct the RSEI, which integrates with the green degree, humidity, dry degree, and heat degree. Then, we quantitatively evaluated the ecological environmental quality of Jinan from 2006 to 2018 and analyzed the temporal and spatial evolution of the quality of the ecological environment in Jinan. Finally, the influencing factors of the quality of ecological environment change of Jinan are discussed. From 2006 to 2018, the ecological environmental quality of Jinan shows a " $V$ " trend of declination first and then increased. The proportion of areas where the ecological environment in Jinan was improved at $32.78 \%$, unchanged at $48.82 \%$, and decreased by only $18.40 \%$, respectively. The areas with the poor ecological environment are mainly distributed in the eastern urban area and the northern plain area, and the areas with the improved environment are mainly distributed in the southern mountainous area. The improvement of the ecological environment in Jinan is mainly due to the effective policies of the local government and the active protection of the masses.

The research results of this paper provide a scientific basis for the urban construction of Jinan, thereby promoting the sustainable development of resources and the environment in the study area. Future research would continue to explore the combination of Sentinel-2, GF-2, and other multi-source data to evaluate the quality of the ecological environment.

\section{Acknowledgments}

This research was financially supported by the Hebei Key Laboratory of Earthquake Dynamics (grant number FZ212203), and by the Open Research Fund of National Earth Observation Data Center (grant number NODAOP2020008), and by the MOE Layout Foundation of Humanities and Social Sciences (grant number 17YJAZH013).

\section{Conflict of Interest}

The authors declare no conflict of interest.

\section{References}

1. DEDEKORKUT-HOWES A., TORABI E., HOWES M. Planning for a different kind of sea change: lessons from Australia for sea level rise and coastal flooding. Climate Policy, 21 (2), 152, 2021.

2. MARFAI M.A., KING L. Potential vulnerability implications of coastal inundation due to sea level rise for the coastal zone of Semarang city, Indonesia. Environmental Geology, 54 (6), 1235, 2008.

3. HASAN M.E., ZHANG L., DEWAN A., GUO H.D., MAHMOOD R. Spatiotemporal pattern of forest degradation and loss of ecosystem function associated with Rohingya influx: A geospatial approach. Land Degradation \& Development, 2020.

4. ADNAN M.S.G., ABDULLAH A.M., DEWAN A., HALL J.W. The effects of changing land use and flood hazard on poverty in coastal Bangladesh. Land Use Policy, 99, 104868, 2020.

5. LI G.Y., CHEN S.S., YAN Y., YU C. Effects of urbanization on vegetation degradation in the Yangtze River Delta of China: Assessment based on SPOT-VGT NDVI. Journal of urban planning and development, 141 (4), 05014026, 2015.

6. LI D.L., WU S.Y., LIANG Z., LI S.C. The impacts of urbanization and climate change on urban vegetation dynamics in China. Urban Forestry \& Urban Greening, 54, 126764, 2020.

7. CARPIO M., GONZALEZ A., GONZALEZ M., VERICHEV K. Influence of pavements on the urban heat island phenomenon: A scientific evolution analysis. Energy and Buildings, 226, 110379, 2020.

8. LI Y.X., ZHANG X.K., ZHU S.J., WANG X.Y., LU Y.D., DU S.H., SHI X. Transformation of urban surfaces and heat islands in Nanjing during 1984-2018. Sustainability, 12 (16), 6521, 2020.

9. ZENG S.Y., MA J., YANG Y.J., ZHANG S.L., LIU G.J., CHEN F. Spatial assessment of farmland soil pollution and its potential human health risks in China. Science of the Total Environment, 687, 642, 2019.

10. YANG G.R., CHEN L.R., LIN D.M. Status, sources, environmental fate and ecological consequences of microplastic pollution in soil. China Environmental Science, 41 (1), 353, 2021.

11. LIU Y.H., LI Z.Q., WEI B.Y., LI X.L., FU B. Seismic vulnerability assessment at urban scale using data mining and GIScience technology: application to Urumqi (China). Geomatics, Natural Hazards and Risk, 10 (1), 958, 2019. 
12. LIU Y.H., SO E., LI Z.Q., SU G.W., GROSS L., LI X.L., QI W.H., YANG F., FU B., YALIKUN A., WU L.J. Scenariobased seismic vulnerability and hazard analyses to help direct disaster risk reduction in rural Weinan, China. International Journal of Disaster Risk Reduction, 48, 101577, 2020.

13. LI X.Y., MA Y.J., XU H.Y., WANG J.H., ZHANG D.S. Impact of land use and land cover change on environmental degradation in Lake Qinghai watershed, northeast Qinghai-Tibet Plateau. Land Degradation \& Development, 20 (1), 69, 2009.

14. LI Z., PAN J.H. Spatiotemporal changes in vegetation net primary productivity in the arid region of Northwest China, 2001 to 2012. Frontiers of Earth Science, 12 (1), 108, 2018.

15. YOHANNES H., SOROMESSA T., ARGAW M., DEWAN A. Changes in landscape composition and configuration in the Beressa watershed, Blue Nile basin of Ethiopian Highlands: historical and future exploration. Heliyon, 6 (9), e04859, 2020.

16. YOHANNES H., SOROMESSA T., ARGAW M., DEWAN A. Spatio-temporal changes in habitat quality and linkage with landscape characteristics in the Beressa watershed, Blue Nile Basin of Ethiopian highlands. Journal of Environmental Management, 281 (2), 111885, 2021.

17. YANG Y.J., ZHENG Z.F., YIM S.Y.L., ROTH M., REN G.Y., GAO Z.Q., WANG T.J., LI Q.X., SHI C.N., NING G.C., LI Y.B. PM2.5 pollution modulates wintertime urban heat island intensity in the Beijing-Tianjin-Hebei Megalopolis, China. Geophysical Research Letters, 47 (1), e2019GL084288, 2020.

18. XU H.Q. A remote sensing urban ecological index and its application. Acta Ecologica Sinica, 33 (24), 7853, 2013.

19. YUE H., LIU Y., LI Y., LU Y. Eco-environmental quality assessment in China's 35 major cities based on remote sensing ecological index. IEEE Access, 7, 51295, 2019.

20. HANG X., LI Y.C., LUO X.C., XU M., HAN X.Z. Assessing the ecological quality of Nanjing during its urbanization. Journal of Meteorological Research. 34 (2), 280, 2020.

21. RUKEYA-S., ABUDUHENI-A., LI H. Dynamic monitoring and analysis of ecological environment in Fukang City based on RSEI model. Research of Soil and Water Conservation, 27 (1), 283, 2020.

22. XIONG Y., XU W.H., HUANG S.D., WU C., DAI F., WANG L.G., LU N., KOU W.L. Ecological environmental quality assessment of Xishuangbanna rubber plantations expansion (1995-2018) based on multi-temporal Landsat imagery and RSEI. Geocarto International, 2020.

23. ZHANG H., SONG J.Y., LI M., HAN W.H. Ecoenvironmental quality assessment of Qilian Mountain National Park based on GEE. Chinese Journal of Ecology, 40 (06), 1883, 2021.

24. LIU W.J., JIAO F.C., REN L.J., XU X.G., WANG J.C., WANG X. Coupling coordination relationship between urbanization and atmospheric environment security in Jinan City. Journal of Cleaner Production, 204, 1, 2018.

25. CHENG M.T., TANG G.Q., LV B., LI X.R., WU X.R., WANG Y.M., WANG Y.S. Source apportionment of PM2.5 and visibility in Jinan, China. Journal of Environmental Sciences, 102, 207, 2021.

26. LIU Y.Y., WANG J., ZHAO X.Y., WANG J., WANG X.H., HOU L.J., YANG W., HAN B., BAI Z.P. Characteristics, secondary formation and regional contributions of PM2.5 pollution in Jinan during winter. Atmosphere, 11 (3), 273, 2020.
27. HONG Q.A., MENG Q.B., WANG P., WANG H.Y., LIU R.M. Regional aquatic ecological security assessment in Jinan, China. Aquatic Ecosystem Health \& Management, 13 (3), 319, 2010.

28. ZHANG X., XU Z.X., YIN X.W., YU S.Y., DOU T.W. Aquatic ecosystem function zoning in Jinnan. Journal of Beijing Normal University(Natural Science), 52 (3), 303, 2016.

29. XU J., XU Z.H., LI W., WANG X.R., WANG X. Temporal and spatial changes of rainfall erosivity during 1970-2016 in Jinan. China. Mountain Research, 36 (3), 391, 2018.

30. SUN Y.L., ZHU H.K. A pilot study of organophosphate esters in surface soils collected from Jinan City, China: implications for risk assessments. Environmental Science and Pollution Research, 28 (3), 3344, 2020.

31. WANG Y.L., SHENG K.R., SONG M.J. Temporal-spatial evolution and simulation prediction of land use and landscape patterns in Jinan from 1980 to 2015. Journal of University of Jinan (Science and Technology), 34 (3), 282, 2020.

32. RONG L.Y. Research on spatial relationship of Jinan vitality center. Master Degree Thesis. Jinan: Shandong Jianzhu University, 2019.

33. ZHU J. Analysis of Landsat8 satellite remote sensing data preprocessing. Remote Sensing for Land and Resources, 28 (2), 21, 2016.

34. XU H.Q. A remote sensing index for assessment of regional ecological changes. China Environmental Science, 33 (5), 889, 2013.

35. LI N., WANG J., QIN F. The improvement of ecological environment index model RSEI[J]. Arabian Journal of Geosciences, 13 (11), 2020.

36. CRIST E.P. A TM Tasseled Cap equivalent transformation for reflectance factor data. Remote Sensing of Environment, 17 (3), 301, 1985.

37. XIONG Y., XU W.H., LU N., HUANG S.D., WU C., WANG L.G., DAI F., KOU W.L. Assessment of spatialtemporal changes of ecological environment quality based on RSEI and GEE: A case study in Erhai Lake Basin, Yunnan province, China. Ecological Indicators, 125, 107518, 2021.

38. XU H. A new index for delineating built-up land features in satellite imagery. International Journal of Remote Sensing, 29 (14), 4269, 2008.

39. LIU C., YANG M.H., Hou Y.T., ZHAO Y.N., Xue X.Z. Spatiotemporal evolution of island ecological quality under different urban densities: A comparative analysis of Xiamen and Kinmen Islands, southeast China. Ecological Indicators, 124, 107438, 2021.

40. ZHANG C.C., CHEN D.H., DONG H.T. Land surface temperature retrieval based on "Landsat-5" TM data in Baisha Irrigation of Henan province. Remote Sensing Technology and Application, 28 (6), 964, 2013.

41. XU H.Q. A study on information extraction of water body with the modified normalized difference water index (MNDWI). Journal of Remote Sensing, 9 (5), 589, 2005.

42. WANG L.C., JIAO L., LAI F.B., ZHANG N.M. Evaluation of ecological changes based on a remote sensing ecological index in a Manas Lake wetland, Xinjiang. Acta Ecologica Sinica, 39 (8), $2963,2019$.

43. CHEN W., HUANG H.P., TIAN Y.C., DU Y.Y. Monitoring and assessment of the eco-environment quality in the Sanjiangyuan region based on Google Earth Engine. Journal of Geo-information Science, 21 (9), 1382, 2019. 